\title{
Students' Units Coordination Activity: A Cross-Sectional Analysis
}

\author{
Anderson Norton \\ Virginia Tech \\ 540-231-6942 \\ norton3@vt.edu
}

\author{
Steven Boyce \\ Portland State University
}

\author{
Catherine Ulrich \\ Nathan Phillips \\ Virginia Tech
}

\begin{abstract}
Students' ability to coordinate multiple levels of units constitutes a cognitive core in their mathematical development across several domains, including counting, whole number multiplication, integer addition, fractions concepts, and algebraic reasoning. Identifying a progression of students' units coordination activity would help educators leverage and support student development within and across the three stages of units coordination. This paper contributes to that goal by describing a cross-section of units coordination activity observed during pairs of clinical interviews with 47 grade 6 students. Results include a 36-rank scale of units coordinating activity with accompanying characterizations and descriptors.
\end{abstract}


Keywords: cross-sectional analysis; mathematical development; middle school; units coordination

Recent studies have identified students' inability to coordinate two and three levels of units as a root cause for poor performance across several domains in middle school mathematics, including fractions concepts (Hackenberg \& Tillema, 2009; Izsák, Jacobsen, de Araujo, \& Orrill, 2012; Norton \& Boyce, 2013; Steffe \& Olive, 2010), algebraic reasoning (Hackenberg, 2013; Olive \& Çağlayan, 2008), and integer addition (Ulrich, 2013). The construct developed out of Steffe's work with both whole (e.g., 1992, 1994) and fractional (e.g., 2001, 2010) number learning. In his words, "I think of units coordinating as the mental operation of distributing a composite unit across the elements of another composite unit" (1992, p. 279). For example, multiplying 7 by 5 could involve the units coordination of distributing 7 units of 1 across each unit of the 5 to produce a unit (35) that, in the learner's mind, is composed of five units of seven 1s each.

Throughout this paper, we refer to stages of units coordination to indicate progressively sophisticated ways in which students coordinate units. To illustrate these stages, consider the Vacation Problem (Hackenberg \& Tillema, 2009): “We've been on vacation for five weeks. How many days have we been on vacation?" Table 1 shows how students at each stage typically approach this problem, depending on the number of levels of units they take as given and the number of levels they coordinate in activity. "Take as given" refers to what students can assimilate into their existing cognitive structures without the need to engage in further activity (Piaget, 1970). In contrast, "in activity" refers to structures that students can build up through some kind of imagined or physical action. 
Table 1. Units coordination with whole numbers.

\begin{tabular}{|l|l|l|}
\hline Stage & $\begin{array}{l}\text { Students' Ways of } \\
\text { Coordinating Units }\end{array}$ & Students' Reasoning on the Vacation Problem \\
\hline $\mathbf{1}$ & $\begin{array}{l}\text { Students can take one } \\
\text { level of units as given, and } \\
\text { may coordinate two levels } \\
\text { of units in activity. }\end{array}$ & $\begin{array}{l}\text { Students keep track of how many times they run through } \\
\text { a unit of 7. For example, they might say, "7 that's 1 } \\
\text { week; 14 that's 2 weeks; 15, 16, 17, 18, 19, 20, 21, that's } \\
\text { 3 weeks;" etc. }\end{array}$ \\
\hline $\mathbf{2}$ & $\begin{array}{l}\text { Students can take two } \\
\text { levels of units as given, } \\
\text { and may coordinate three } \\
\text { levels of units in activity. }\end{array}$ & $\begin{array}{l}\text { Students take the composite units of 7 and 5 as given, so } \\
\text { they start with the goal of determining the value of five } \\
\text { 7s. They might reason as follows: "Two 7s is 14, and two } \\
\text { more 7s makes 28; then one more 7 would be... 35." }\end{array}$ \\
\hline $\mathbf{3}$ & $\begin{array}{l}\text { Students can take three } \\
\text { levels of units as given, } \\
\text { and can flexibly switch } \\
\text { between three-levels-of- } \\
\text { units structures. }\end{array}$ & $\begin{array}{l}\text { Students can take the quantity formed by seven 5s as } \\
\text { given, even before they determine its value. They know } \\
\text { this is the same quantity formed by five 7s, so they can } \\
\text { determine the value by reasoning as follows: "Five 7s is } \\
\text { the same as seven 5s and I'd rather work with fives } \\
\text { because they're easier: Five 5s is 25, and two more 5s } \\
\text { makes 35." }\end{array}$ \\
\hline
\end{tabular}

We emphasize that these stages do not describe fluency with multiplication facts per se, but rather describe the psychological structures with which students operate (Piaget, 1970). For example, in a teaching experiment with a 6th grade student named Cody (Norton \& Boyce, 2013), the first author (as teacher-researcher) observed that Cody could use many multiplication facts (e.g., 8 × $3=24$ and 6 × $6=36$ ) and could compute more complicated products (e.g., 7 x 12 $=84$ ) by imagining the standard algorithm. Yet, when he asked Cody to determine the number of chips in 8 cups, if each cup contained 3 chips, despite repeated cues regarding the number of cups and the number of chips per cup, Cody seemed to have no way to respond except to count the chips by pointing to each cup and reciting his number sequence in groups of 3 (" $1,2,3 ; 4,5$, $6 ; \ldots$;) - a distinguishing feature of Stage 1 thinking.

Cody's example demonstrates that instead of referring to multiplication facts and skills, stages of units coordination refer to students' progress in constructing mental structures, like the 
one represented in Figure 1 (here, "35" is conceived of as a unit composed of five units, each composed of seven units of 1), to help them understand and operate flexibly in novel mathematical situations. While Cody knew his multiplication tables and a multiplication algorithm, he had not constructed a sophisticated way of understanding and operating in situations involving, to the observer, multiple levels of units.

a unit of five units each containing seven units

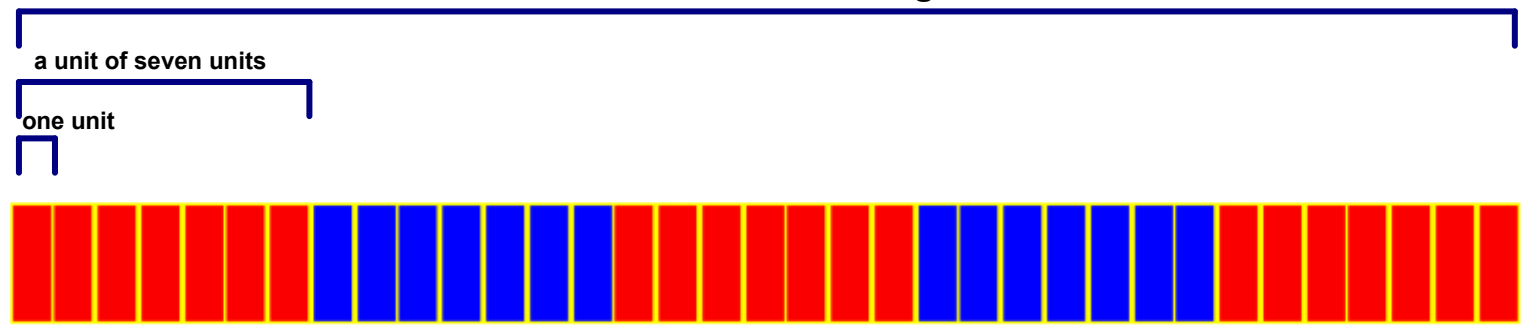

Figure 1. A structure for coordinating three levels of units (Hackenberg \& Lee, 2015).

Students' construction of such structures has implications beyond whole number knowledge. As elaborated in the next section, students operating at Stages 1 or 2 think in ways that significantly constrain their ways of operating in the domains of fractions concepts, integer addition, and algebraic reasoning (Hackenberg, 2013; Steffe \& Olive, 2010; Ulrich, 2013). These difficulties for students operating at Stages 1 and 2 become especially alarming when we consider the percentages of students at each stage entering middle school. Steffe (2007) has estimated that, by the end of fifth grade, $30-50 \%$ of students operate at Stage 1 (e.g., Cody), where the remainder of the population is comprised of students operating at Stages 2 or 3. Coordinating additional units, i.e., moving from one stage to the next, requires a substantial reorganization in students' ways of operating, which can take as long as two years (Steffe \& 
Cobb, 1988; Steffe \& Olive, 2010). Thus, we need a more fine-grained understanding of how students progress within and across stages so that educators can assess and foster incremental growth towards Stage 3 reasoning.

The purpose of this study is to map a hierarchy of units coordinating activity within and across developmental stages. What does student activity look like within Stages 1 and 2, and how does that activity develop toward Stage 3? Our data come from pairs of video-recorded clinical interviews with 47 sixth-grade students in a rural, high-needs school. We analyzed the first set of interviews with these 47 students to identify a cross-section of units coordinating activity. Our analysis resulted in 36 distinct rankings, which we tested by comparing it to students' units coordinating activity in the second set of interviews. Because we conducted interviews with 47 students, we are able to generate a more detailed mapping than anything the research community has produced so far.

\section{Units Coordination}

Throughout their schooling experiences, students' abilities to build and coordinate units influence many facets of their mathematical thinking and activity. In this section, we elaborate on how students at each stage might coordinate units across various domains of mathematical activity, beginning with counting.

\section{Units Coordination and Number Sequences}

"A number sequence can be thought of as a sequence of abstract unit items that contain records of counting" (Steffe, 1992, p. 263). The first two number sequences that children construct - the Initial Number Sequence (INS) and the Tacitly Nested Number Sequence (TNS) - correspond with units coordination Stage 1. Using an INS, a student can count by 1s 
(e.g., "one, two, three, four") and even count on from any point in the number sequence (e.g., "five, six, seven"), but when students count on, the initial number (4) is only a record of counting activity and not itself a unit. Once students unitize their records of counting, they begin coordinating two levels of units in the activity of counting - the 1s being counted and the composite unit containing those 1s. This is the distinguishing feature of the TNS, which enables students to double count (e.g., three 4s as "one, two, three, four; that's 1. Five, six, seven, eight; that's 2. Nine, ten, eleven, twelve; that's 3").

The Explicitly Nested Number Sequence (ENS) corresponds with Stage 2. For students operating with an ENS, students can use composite units in iteration; i.e., these students can iterate a composite unit to produce a unit of units of units in activity (e.g., building up 12 as three units of four $1 \mathrm{~s}$ by physically or imaginatively iterating a composite unit of four 1s). Once students can assimilate such situations with three-level unit structures, without the need to build them through activity, we say that the student has constructed a Generalized Number Sequence (GNS), which corresponds with Stage 3. Thus, number sequences constitute a kind of units coordination by way of the units that students can iterate (units of 1 or composite units) and the number of levels of units students can assimilate.

\section{Units Coordination and Multiplicative Reasoning}

Hackenberg (2010) has characterized students' units coordinating activity in terms of multiplicative concepts. She distinguished three stages of multiplicative reasoning corresponding to the three stages and examples in Table 1. Students at Stage 1 operate with the first multiplicative concept (MC1) with which they can coordinate two levels of units in activity. Students at Stage 2 operate with the second multiplicative concept (MC2) with which they can take two levels of units as given and coordinate three levels of units in activity. Students at Stage 
3 operate with the third multiplicative concept (MC3) with which they can take three levels of units as given.

One important feature of MC3 students is that they can reverse their multiplicative reasoning in both whole number and fractions contexts (Hackenberg, 2010). For example, consider the following task: "Sara's stack of CDs is $65 \mathrm{~cm}$ tall. That's 5 times the height of Roberto's stack of CDs. Can you draw a picture of this situation? How tall is Roberto's stack?" (p. 402). MC3 students understand that 65 is the result of iterating an unknown quantity 5 times, and they can determine this unknown quantity by operating on 65 in the reverse directionundoing the iterations by partitioning or dividing.

MC2 students can begin solving such tasks too. For instance, consider the case of a sixthgrade student, named Carlos, who participated in a teaching experiment with Hackenberg (2010). Early in the teaching experiment, Carlos had unsuccessfully attempted to solve the following task: "A 2-foot bar is three times the length of your candy bar. Make your candy bar and tell me how long it is (no erasing the foot-mark)" (p. 410). A few weeks later, Carlos suggested that he might break up each of the two feet within the two-foot bar into pieces so that he could group them into three equal parts. It seems that Carlos knew he could reverse the iteration ("three times") by partitioning, but he did not know many parts should be in each foot or how big those parts should be. These parts introduced a third level of units that he had not assimilated into the situation he experienced.

\section{Units Coordination with Fractions}

Steffe's (2001) reorganization hypothesis posits a direct connection between students' ways of operating with units across whole numbers and fractions: "Children's fractions schemes can occur as accommodations in their numerical counting schemes" (p. 267). Students operating 
with a TNS (Stage 1; MC1) can begin to understand fractions as parts within wholes. For example, they can understand 5/7 as five equal parts within a whole that has been partitioned into seven equal parts. However, limitations in their units coordinations preclude them from disembedding 5/7 from the whole without destroying the whole (Steffe \& Olive, 2010). In other

words, they cannot simultaneously consider $5 / 7$ as five parts taken out of the whole and as five of the seven parts making up the whole.

More generally, students operating at Stage 1 do not conceptualize size relationships between unit fractions and the whole. To do so would require them to conceptualize $1 / 5$ as a unit and the whole as a unit that is five times as big (Olive \& Vomvoridi, 2006) — a way of operating associated with Stage 2 (Steffe \& Olive, 2010). One consequence is that students operating at Stage 1 may not understand the reciprocal relationship between the number of parts in a whole and the size of each part (Biddlecomb, 2002). For students operating at Stages 2 and 3, such understanding is contained within their units coordinating structures, and students operating at these stages can begin conceptualizing fractions in more and more sophisticated ways (Boyce \& Norton, in review; Steffe \& Olive, 2010). For example, students operating at Stage 3 can work flexibly within a three-level structure for an improper fraction such as 7/5: the unit fraction (1/5), the whole (5/5), and the improper fraction itself (Hackenberg, 2007).

\section{Units Coordination with Integers}

We have been focusing on the multiplicative coordination of units. The introduction of negative numbers into a student's numerical world involves additive coordinations of numbers (Ulrich, 2013). In particular, we often use signed numbers in middle school and beyond to describe the relative increase (positive) or decrease (negative) of an ending amount in relation to a starting amount. Because Stage 1 students can iterate a unit of 1, they can use an integer to 
describe the result of an additive comparison between an ending and starting amount (e.g., "41, $40,39,38,37,36 ; 41$ to 36 was a decrease of 5 , so -5 ”'). Furthermore, some Stage 1 students can build a composite unit to represent the increase or decrease and coordinate certain changes to the change and the ending amount (e.g., "If we were going to 34 instead, we'd have to go two more, so that would be a decrease of 7").

Because all of these coordinations are taking place in activity, the Stage 1 student will have trouble keeping track of how the starting amount, ending amount, and additive comparison are related once more complicated operations are required. One symptom of this would be a student who regularly conflates the change in position on the number line with the endpoint of change once he starts combining or comparing multiple changes of position. For example, consider the following typical Stage 1 response: "I started at $+24 \mathrm{~m}$ above sea level and then decreased my elevation by $33 \mathrm{~m}$. That puts me...[acting it out on a number line]...here." If asked how far the student went, he may say $9 \mathrm{~m}$, and asked where he is, he might say -33 , conflating the change in position, -33 , with the endpoint, -9 . For Stage 2 students, composite units have a more immediate, multiplicative relationship to their constituent units of 1 than the composite units of Stage 1 students, and this allows them to build more stable three-level structures. In particular, Stage 2 students are less likely to conflate additive comparisons and ending amounts when working with integers.

\section{Units Coordination in Algebraic Reasoning}

Researchers are also coming to understand how units coordination influences students' algebraic reasoning (e.g., Ellis, 2007; Hackenberg, 2013; Olive \& Caglayan, 2008). Hackenberg (2013) has found that because students operating at Stage 1 need to build composite units of length through activity, they do not readily represent an unknown length with a letter. Students 
operating at Stage 2 use letters to represent unknown lengths, but they do not use whole numbers or fractions as multipliers on unknowns (Hackenberg \& Lee, 2015). As a consequence, they do not readily represent generalized multiplicative relationships with algebraic equations. For example, consider the CD task: "Theo's has a stack of CDs some number of centimeters tall; Sam's stack is $2 / 5$ of that height. Can you write an expression for how tall the height of Sam's stack is?" Students operating at Stage 2 might write "S $+3 / 5=$ T." In contrast, students operating at Stage 3 can write equations like $S=2 / 5 \mathrm{~T}$.

Hackenberg \& Lee's (2015) study suggests that only students operating at Stage 3 can independently build equations representing multiplicative relations and unknown quantities. Olive and Caglayan (2008) found similar results when working with students in a discrete context involving money. In addition, Ellis' (2007) study on co-variational reasoning suggests that students have to construct emergent ratios between co-varying quantities in order to develop robust understandings of function. As a quantity constructed from two other quantities (involving three levels of units), emergent ratios are only in the province of Stage 3 students.

\section{Summary}

Looking across the content domains, we can identify characteristics of units coordinating activity at each stage, as distinguished by the number of levels of units with which students operate at one time. Whereas students operating at Stage 1 can iterate units of 1, students operating at Stages 2 and 3 can iterate composite units and their constituent units of 1

simultaneously (Steffe, 1992). Students operating at Stage 2 can also build a three-level structure through activity, but only Stage 3 students use such structures to assimilate problem situations. Thus, in problem situations involving three levels of units, we should expect to see greater flexibility among students operating at Stage 3 . 
The ability to iterate composite units provides opportunity for students operating at Stage 2 to engage in further units coordinating activity. In particular, they can distribute the units of one composite unit across the units of another composite unit: Students operating at Stage 2 do this in activity; and students operating at Stage 3 can anticipate such activity without having to carry it out (Steffe, 1992). Distributing composite units enables students to build multiplicative relationships and even reverse those relationships (Hackenberg, 2010). In the domain of fractions, Stage 2 and 3 students can establish the reciprocal relationship between the number of equal parts in a whole and the size of each part (Hunting, 1983), and they can build three-level structures for conceptualizing improper fractions (Hackenberg, 2007). In other domains, these three-level structures support conceptions of integer addition (Ulrich, 2013) and algebraic equations (Hackenberg \& Lee, 2015)

In line with Piagetian theory (1970), we refer to a units coordinating structure as a system of operations that transforms units. Figure 1 represents a structure in which students might operate across three levels of units (e.g., iterating a composite unit of seven 1s five times to produce 35 as a unit of five units of seven 1s). We refer to units coordinating operations as the mental actions organized within the system (e.g., distributing a composite unit of 5 across seven units of 1). We refer to units coordinating activity as the observable behaviors students carry out that might indicate their units coordinating structures and operations. Our study focused on units coordinating activity, in an attempt draw fine-grained distinctions between students' units coordinating operations and structures.

\section{Methods}


To elicit students' units coordinating activity, we conducted pairs of one-on-one clinical interviews with 47 students. The first two authors used the first set of interviews to rank students' units coordination activity and to generate characterizations for activity at each rank. Through further analysis, the first two authors generated a 36-rank scale of units coordinating activity. Then, the last two authors used the second set of interviews, along with the scale and descriptors, to place the same 47 students on the 36-rank scale. Finally, we conducted quantitative analyses to test the reliability and construct validity of the scale as a fine-grained hierarchy of students' units coordinating activity.

\section{Clinical Interviews}

We conducted the clinical interviews (Clement, 2000) with students from a rural middle school in the Southeastern region of the United States. We initially interviewed fifty sixth-grade students (all of the sixth-grade students in the school who returned a signed parent permission form) during a three-day period in the second week of the school year, in August 2012. Each interview was conducted by one of the first two authors during the normal class time, in a separate classroom. The first author conducted 26 of the interviews. Each interview lasted approximately 15 minutes.

We conducted the second set of interviews in the same manner, with 47 of the 50 students we had initially interviewed. The other three students were unavailable for second interviews, leaving 47 students for our matched-pair study. The first author conducted 25 of

these interviews. We conducted these interviews during the third week of November, 2012. There was approximately 12 weeks between the first and second set of interviews. We used the same tasks for both sets of interviews.

\section{Clinical Interview Tasks}


We used two types of tasks to assess students' ways of operating with units. The first type involved rectangular bars made of colored construction paper (see Figure 3). The interviewer put a red bar that was 9 inches long and a yellow bar that was 2.25 inches long on the student's desk, and asked, "How many times does the yellow bar fit into the red bar?" The student could manipulate the bars in response, and if " 4 " was not the result (e.g., due to estimation or counting errors) then the interviewer would ask the student to repeat the process in order to establish that the yellow bar fit into the red bar 4 times. The red bar was then removed from view, and a blue bar that was 0.75 inches long is placed below the yellow bar, with the same line of questioning. Upon a similar establishment that the blue bar fit into the yellow bar 3 times, the student was asked, "Without using the bars, and can you decide how many times the blue bar fits into the red bar?" Upon receiving a response, the interviewer encouraged the student to explain by referring to the actual bars.

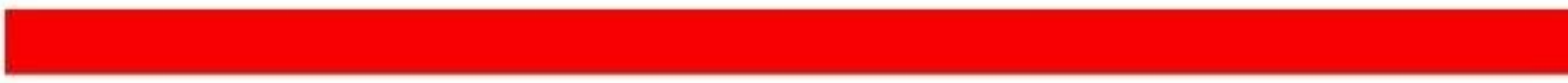

Figure 3. Bars task.

The interviewer then posed three tasks in which the students could not determine numbers of iterations through manipulations of the bars. The original bars were removed from the table, and a red bar of length $25 \mathrm{~cm}$, a yellow bar of length $7 \mathrm{~cm}$, and a blue bar of length 3 
$\mathrm{cm}$ were placed on the desk (see Figure 4). After each task, the interviewer asked the student to explain their reasoning for their response.

1. If the Yellow bar fit into the Red bar 5 times and the Blue bar fit into the Yellow bar 2 times, how many times would the Blue bar fit into the Red bar?

2. If the Yellow bar fit into the Red bar 5 times and the Blue bar fit into the Red bar 15 times, how many times would the Blue bar fit into the Yellow bar?

3. If the Blue bar fit into the Red bar 8 times and the Blue bar fit into the Yellow bar 4 times, how many times would the Yellow bar fit into the Red bar?

Figure 4. Indeterminate bars tasks.

The second type of task pertained to students' assimilation of an experientially real problem situation concerning desks in a classroom. "In a classroom, there are 6 rows with 4 seats in each row. The teacher adds 12 more seats to the classroom. How many total rows can be made with four seats in each row? How many seats will be in the classroom?" The interviewers asked students to respond to the first question before posing the second question. If students gave a correct response of ' 9 ,' then the second question was asked immediately, before a request for an explanation of the student's reasoning. The interviewers asked students to attempt to respond to both questions without use of figurative material, although some students made gestures on their desks with their fingers. If students were not successful in their solution method or explanation, they were provided with pencil and paper upon request and asked to try again.

\section{Ranking and Descriptors}

The first two authors conducted independent video analyses to assess each student's units 
coordinating stage based on student responses to tasks and the inferences we made about the number of levels of units the student could take as given (see Table 1). Furthermore, they independently ranked all 47 students on an ordinal scale (from least to most sophisticated) and characterized each student's units coordinating activity. This was done independently of stage assessments so that rankings did not necessarily fall within stage assessments. Characterizations and rankings were based on previous studies cited in the units coordination section. Many of these indicators became descriptors for making qualitative distinctions between students' units coordinating activity.

Once the raters had completed their rankings, they met to reconcile their rankings by comparing characterizations. In cases where rankings diverged by 4 or less, the initial ranking was the arithmetic mean of the two rankings. In cases where rankings diverged by 5 or more, the raters reviewed video-recordings of the clinical interviews together to come to a consensus. The raters then made pairwise comparisons of students' characterizations to remove ties in the rankings. With a reconciled ranking from 1-47 established, the raters combined their characterizations for all 47 students.

To further refine the reconciled ranking and characterizations of students' units coordination activity, the first and second authors generated a table for all 47 students (rows), along with descriptors of their units coordinating activity (columns) from the characterizations they had written. The two raters also included four additional rows for descriptors of Stage 3 students' units coordinating activity. These characterizations came from video analyses of clinical interviews conducted in June 2013 by the first, second, and third authors, as part of another study. These interviews also used the indeterminate bars tasks and classroom task, and the participants were sixth-graders from a different school in the same district. The four 
additional characterizations were more advanced than nearly all of the others; including them provided opportunity for each of the 47 students to exhibit growth between August and November.

Each of the descriptor columns was partitioned using qualifications from the raters' characterizations. For example, one of the descriptors arising from characterizations distinguished whether students seemed to iterate composite units. Color-coded distinctions were made within that column depending on whether students could anticipate iterating composite units, whether they did so in activity, or whether they could not do so at all. When no descriptor could be used to distinguish two students' actions, their respective rows were collapsed into a single row. When a descriptor was found to be redundant, in that it did not generate a distinction between any two students, it was removed. The result of this refinement was a table with 36 distinct ranks and 16 descriptors (see Appendix A). Correspondingly, the raters also collapsed their qualitative characterizations for each rank (see Appendix B).

The 36 ranks in Appendix A correspond to the 36 characterizations in Appendix B. As noted above, the first and second authors determined ranks, descriptors, and characterizations independently of their assessments of units coordination stages for the 47 students. However, they had reconciled their assessments of each student's stage, and, after the study, they used these reconciled assessments to demark stages within rankings (Appendix A). They determined the demarcations based on preponderances of stage assessments within the rankings. In particular, 24 of the 27 Stage 1 students appeared in ranks 1-18; 7 of the 10 Stage 2 students appeared in ranks 19-31; and 2 of the 3 Stage 3 students appeared in ranks 32-36. These demarcations appear as thick, horizontal lines in Appendix A.

The third and fourth authors used video-recordings of the second set of clinical 
interviews, along with the table of descriptors (Appendix A without the stage demarcations) and the characterizations (Appendix B), to assign a rank (1-36) to each of the 47 students in the matched-pair study. These authors had not seen the initial interviews for the students they were ranking and were blind to the initial rankings. These authors began by independently ranking 5 of the 47 students. Then they met to reconcile their rankings. Four of their five rankings were within one rank of each other; the remaining one was off by 6 . With their rankings calibrated, the raters independently ranked the remaining 42 students: The third author ranked 30 of them, and the fourth author ranked the other 12 .

\section{Quantitative Analysis}

Quantitative analyses were conducted using R version 2.15 (R Core Team, 2012). As indicators of construct validity, the first two authors calculated two measures of inter-rater agreement. The first measure was a kappa score (Cohen, 1960), to test whether the authors could reliably use descriptions of units coordination in order to assign each of the 47 students to either the Stage 1, 2, or 3. The second measure was Spearman's rank correlation, rho (Best \& Roberts, 1975), to test whether the two authors could generate fine-grained distinctions within those stages by independently assigning each student's units coordinating activity a ranking between 1 and 47 .

Once the second pair of raters had completed their rankings, we conducted a sign test (Lehman, 1975) to determine whether their median rankings based on the second set of interviews differed significantly from the first two authors' rankings based on the initial interviews. We then computed another Spearman rank correlation, across the two sets of interviews. These measures provided an indication of whether mathematics educators could 
reliably use our characterizations and descriptors to assess students' units coordinating activity on a finer scale than what currently exists in the literature.

\section{Results}

Our study consisted of two major phases: the production of the 36 ranks of units coordinating activity and their characterizations; and tests of the reliability and construct validity of those ranked characterizations. The former involved qualitative analysis of observed activity during clinical interviews. The latter involved quantitative measures. We report on results for each phase separately.

\section{Qualitative Results}

Qualitative analysis of the first set of clinical interviews resulted in the ranks and descriptors shared in Appendix A, along with the characterizations shared in Appendix B. We share a sample analysis here, from a student named Carly (pseudonym). Along with one other student, Carly appears at the $19^{\text {th }}$ rank, placing her activity near the middle of the 36 ranks. The analysis shared here illustrates how we arrived at this rank for Carly's units coordinating activity and its associated characterization:

19. The student reliably iterates composite units within multiplicative relationships. The student can use figurative material to build three level structures and use them unambiguously to solve problems, including working in reverse.

For the first bars task, Carly had determined that the blue bar fit into the yellow bar three times and that the yellow bar fit into the red bar four times (see Figure 3). When asked to use that 
information to determine how many times the blue bar fit into the red bar, Carly began looking at the bars intently.

Carly: This [pointing to the yellow bar with her pencil] fits into there [scanning the length of the red bar with her pencil] four times. This [pointing to the blue bar]... You would do 4 times 3, and you'd get 12, maybe.

Interviewer: How do you know to multiply?

Carly: Because you wouldn't add because... Well, you could add. It could be 7 .

Interviewer: How do you know whether to add them or multiply them?

Carly: I'm guessing by looking at them. This [blue bar] would go in 12 and not 7 [scanning length of red bar].

For the next task (Task 1 in Figure 4), the bars were not to scale, so Carly could not rely on how the bars looked. She immediately multiplied the given relations (5 and 2), but she still could not explain why multiplying would produce the unknown relation. For the first reverse task (Task 2 in Figure 4), Carly paused and thought silently for several seconds, looking at the bars. She finally responded "3," explaining, "If this [blue bar] fits into this [red bar] 15 times... You would divide 5 into 15 and get 3." When pressed for the reason she divided, Carly could not explain further. For the second reverse task (Task 3 in Figure 4), Carly responded more quickly: "twice." However, in attempting to explain, she changed her response to "4" and suggested that the blue bar might be half of the yellow bar. As we transitioned to the classroom task, Carly exclaimed, "that's hard!" 
Carly's activity throughout the bars tasks indicated that she could work with three levels of units, but that such activity was cognitively demanding and relied upon the use of figurative material (she was always looking at the bars and sometimes relied on their appearance in finding solutions, even when the bars were not to scale). She seemed to have an intuition about multiplicative relationships, even when working in reverse, but she never explained any of these multiplicative relations. As such, each of the initial raters (first and second authors) independently identified Carly as a student operating at Stage 2 . When ranking her units coordinating activity relative to other students in the study, both raters ranked Carly at the lower end of other Stage 2 students because, relative to them, Carly seemed to rely more heavily on figurative material.

Carly's activity during the classroom task corroborated this assessment. She needed to draw out six columns of four circles before she could make progress in determining the number of additional rows taken up by 12 additional seats. In fact, she proceeded by drawing individual circles across the bottom of the four existing rows, making two more rows as she counted ("1, 2, $3, \ldots, 12$ ") and resulting in a 6-by-6 array. When reminded of the task to determine the total number of rows, she counted the columns and replied "6." Even counting the rows would have produced a total of 6 , because she had already conflated the rows and columns (rows and seats in each row) by using the columns in her drawing to represent rows and by adding the additional seats across the bottom of these six columns (as if she were adding two more rows of 6 rather than three more rows of 4 ).

In sum, Carly consistently attended to three levels of units within a three-level structure, but only by relying on a figurative structure. Even then, she sometimes conflated units (as she had in the final bars task). Along with other students in the study, her activity provided the initial 
interviewers (first and second authors) with the following descriptors: reverses multiplicative relationships (descriptor G); builds a three-level structure (using figurative material; descriptor $\mathrm{H})$; works with at least two levels of units within a figurative three-level structure (descriptor I); (occasionally) conflates units (descriptor O). Descriptors collectively derived from all interviews were applied to all students, although individual interviews provided stronger evidence for some descriptors (e.g., builds composite units, in Carly's case) than others (e.g., indicates a reciprocal relationship between the size and number of parts in a whole, in Carly's case).

\section{Quantitative Results}

Construct validity. The first two raters independently assigned the 47 students into the three stages with an overall agreement of $80.9 \%$. The (unweighted) kappa score of 0.705 suggests that there was substantial agreement in the two raters' assessments (Landis \& Koch, 1977). The cross-tabulations displayed in Table 1 show that nearly half of the 47 students were assessed at Stage 1 by both of the raters, while there were only 3 students assessed at Stage 3 by both raters.

Table 2

Crosstabulation of Rater 1 and Rater 2 Stage Ratings

\begin{tabular}{ccccc}
\hline & \multicolumn{3}{c}{ Rater 2 } & \\
\cline { 2 - 4 } Rater 1 & Stage 1 & Stage 2 & Stage 3 & Total \\
\hline Stage 1 & 23 & 4 & 0 & 27 \\
Stage 2 & 3 & 12 & 2 & 17 \\
Stage 3 & 0 & 0 & 3 & 3 \\
Total & 26 & 16 & 5 & 47
\end{tabular}


The two raters' rankings of the 47 students, on a scale from $1-47$ (from least to most sophisticated activity), were also strongly associated, as illustrated in Figure 5. There were 9 $(21.3 \%)$ cases in which the rankings coincided exactly, and $28(59.6 \%)$ of the raters' rankings were with 4 ranks of each other. Spearman's rank correlation value of $0.929(S=1232, p<.001)$ indicates a strong positive association between the two rankings.

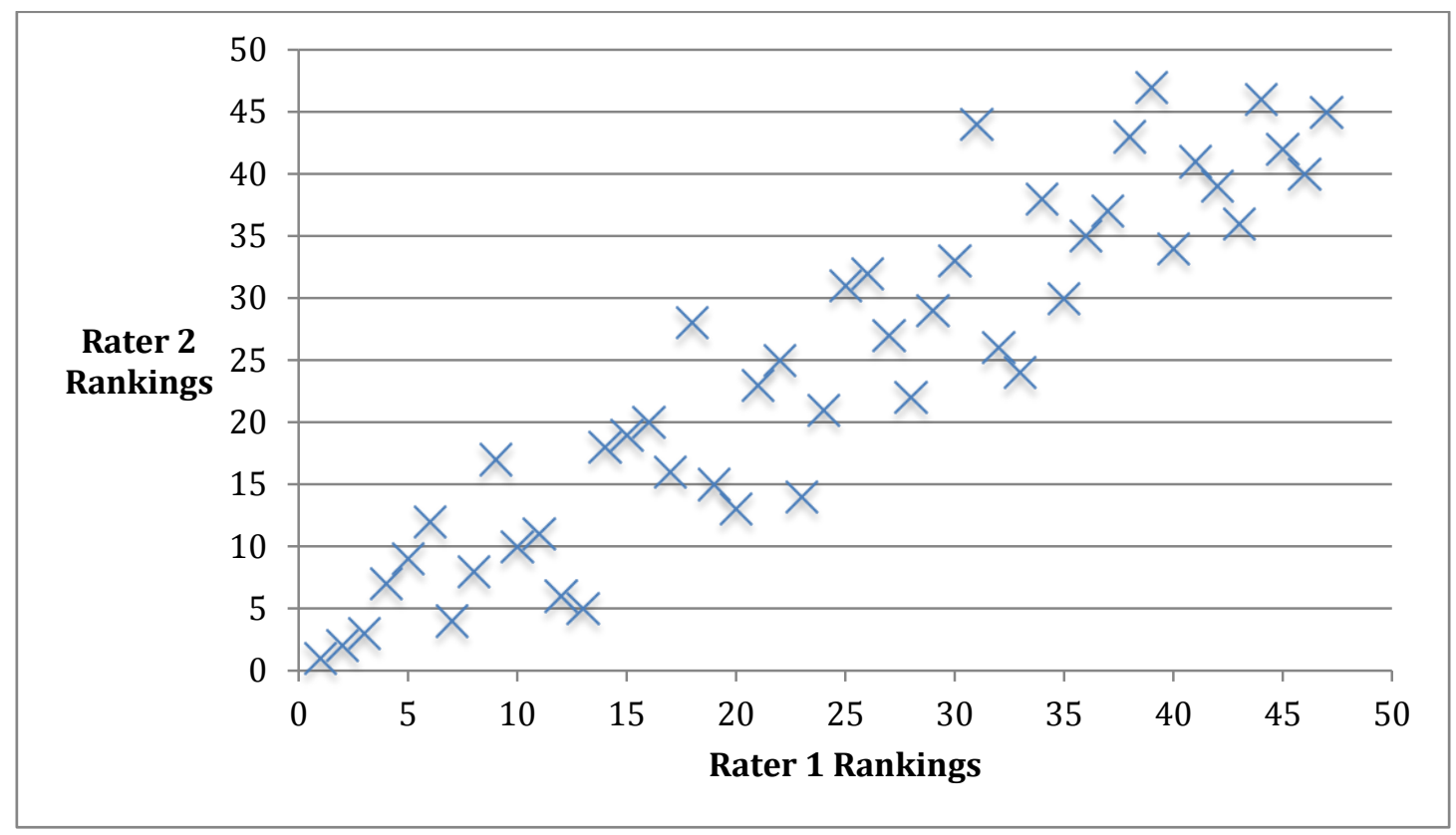

Figure 5. Scatterplot of initial ranking agreement.

Reliability. In the initial ranking of the 47 students, ties were not permitted, and each student was associated with a single ranking and characterization. After collapsing the characterizations to 36 distinct ranks (including the four more advanced characterizations from the other study), ties were both permitted and necessary to rate all 47 students. There was also no 
longer a requirement that each of the 36 ranks be associated with at least one of the 47 students, as descriptions were included to permit inferences of growth in Stage 3 students.

The box plot in Figure 5 displays the distribution of the rankings based on the first and second interviews. The median ranking decreased from 17 to 16 , although the sign test ${ }^{1}$ suggests that the difference is not statistically significant ( $\mathrm{p}=.13$, two-tailed). Spearman's rho value of 0.808 indicates a strong positive association between the ratings made by the first pair of raters using the first set of interviews and the ratings made by the second pair of raters using the second set of interviews $(S=322.794, p<.001)$. As Figure 6 suggests, 31 of the 47 students' rankings changed 6 ranks or fewer between the first and second interviews. Twenty-three of the 47 students' first and second rankings were within three ranks. Of the 16 students whose ranking changed by seven or more ranks, 10 students' rankings decreased, suggesting that large changes in rankings are not generally attributable to students' development over the 3-month period between interviews.

1 The sign test is appropriate because the data are ordinal. The more sensitive Wilcoxon signed rank test (which assumes interval data) also suggests the difference in median ranking is statistically insignificant ( $\mathrm{p}=.07$, two-tailed). 


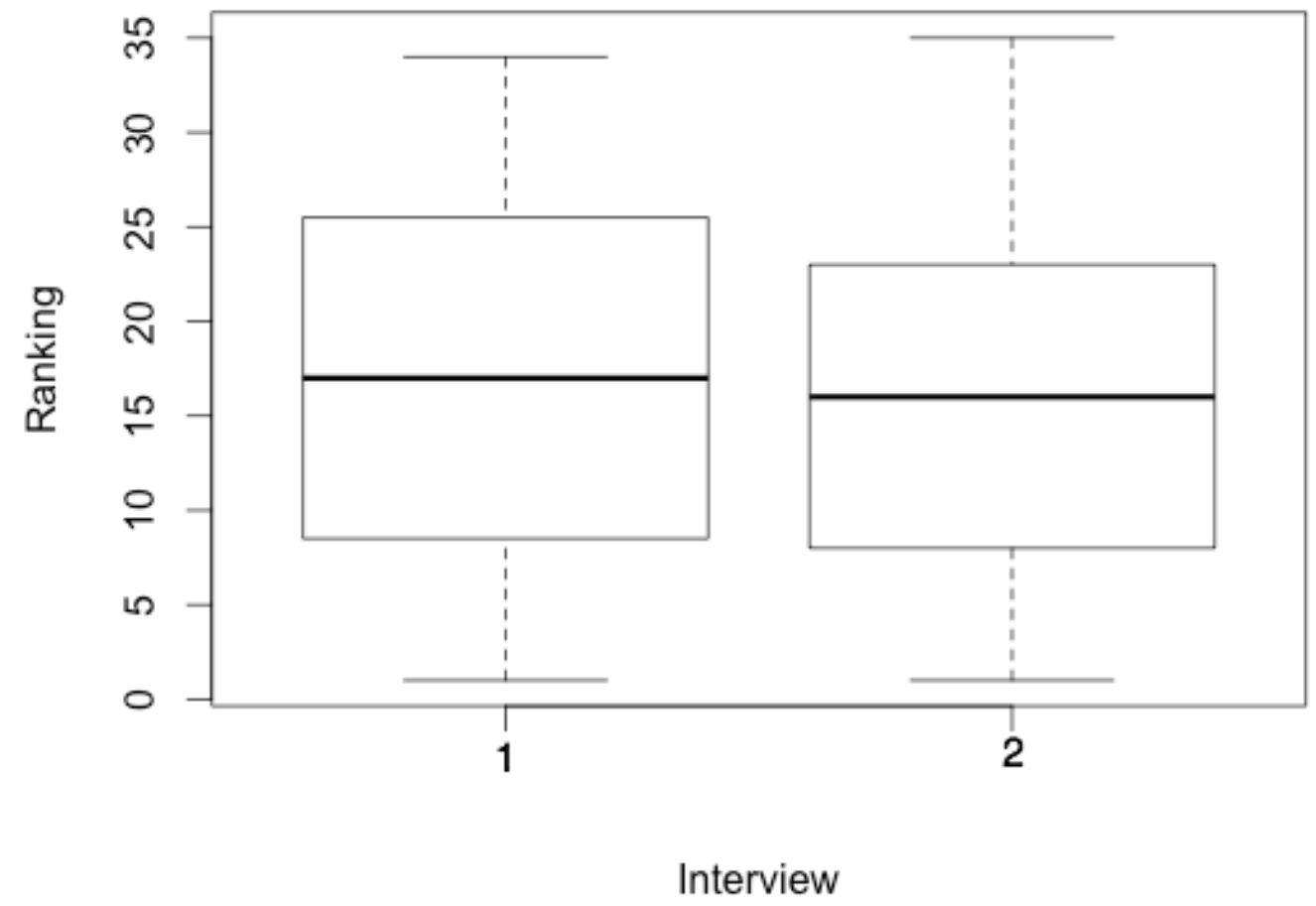

Figure 5. Box plots of rankings of 47 students 


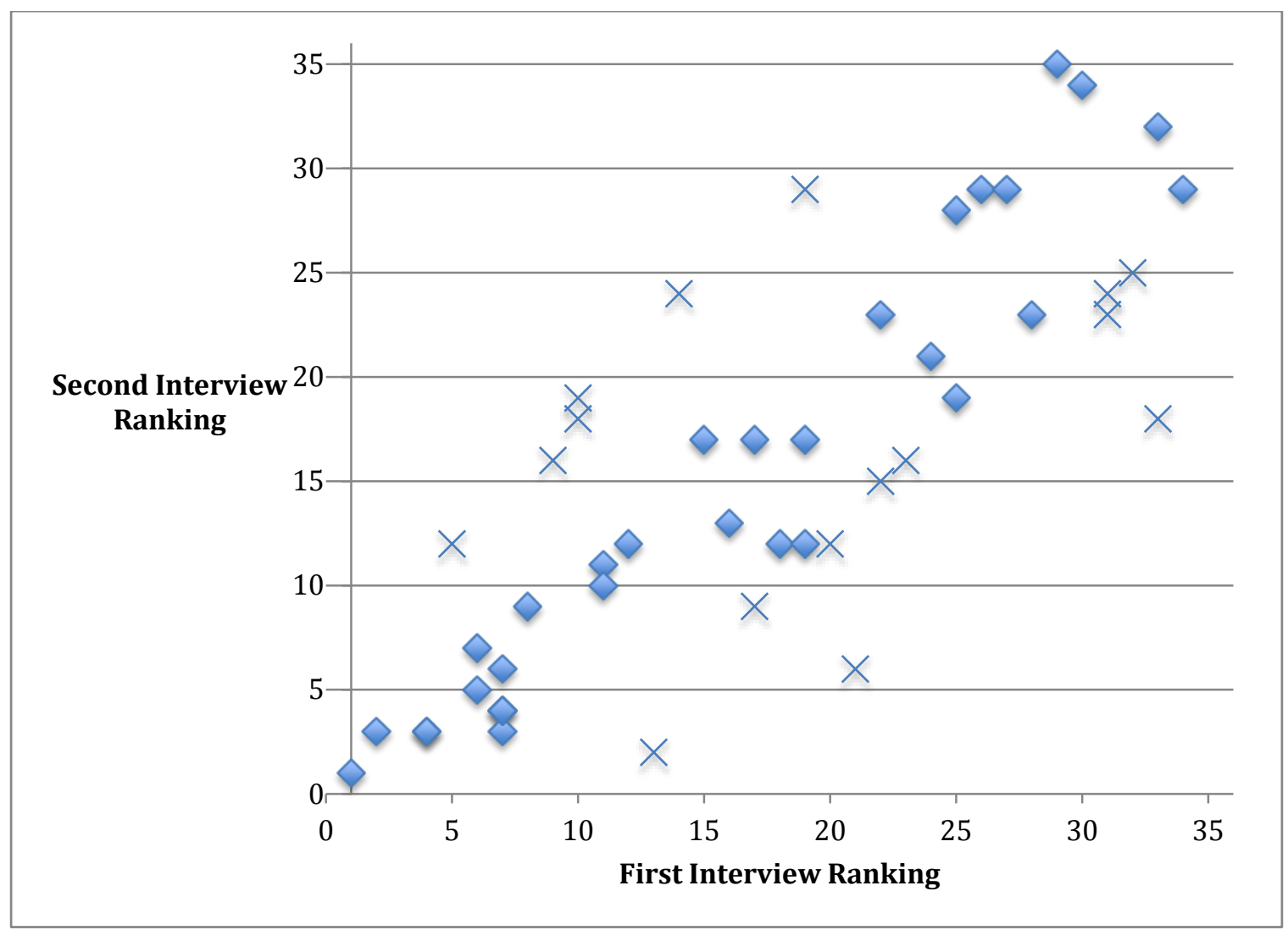

Figure 6. Individuals' rankings on the first and second interviews

\section{Discussion}

Units coordination has arisen as a useful construct for explaining the affordances and constraints of students' ways of operating across multiple domains of mathematics (Hackenberg, 2013; Hackenberg \& Tillema, 2009; Izsák, Jacobsen, de Araujo, \& Orrill, 2012; Norton \& Boyce, 2013; Olive \& Çağlayan, 2008; Steffe \& Olive, 2010; Tillema, 2013; Ulrich, 2012). In our study, substantial agreement across raters validates this three-stage construct (see Table 2), but our main purpose has been to refine descriptions of students' units coordinating activity within and across stages in order to better understand how units coordination operations might develop from Stage 1 to Stage 3. Such understanding will have implications for assessing and supporting that development, which we discuss in the next section. In this section, we discuss the value of our 
descriptors in achieving our purpose, and the degree of granularity that we might achieve in describing students' units coordination activity.

\section{Units Coordination Descriptors}

Using the first set of interviews, the first and second authors were able to identify 36 ranks based on qualitative distinctions in students' units coordinating activity. This ranking was strongly associated with that of the third and fourth authors using the second set of interviews.

We do not claim that these results suggest a new, 36-stage scale for units coordinating operations. Rather, we propose that the qualitative distinctions we have identified could be useful in understanding students' units coordinating activity as they progress toward Stage 3. Consider the 16 descriptors listed in Table 3, on which we based these distinctions.

Table 3. Descriptors of students' units coordinating activity

\begin{tabular}{|l|l|l|l|}
\hline \multicolumn{4}{|c|}{ Descriptors } \\
\hline A. Iterates units of 1 & $\begin{array}{l}\text { E. Works with at least } \\
\text { one level of units } \\
\text { within a figurative } \\
\text { three-level structure }\end{array}$ & $\begin{array}{l}\text { I. Works with at least } \\
\text { two levels of units } \\
\text { within a figurative } \\
\text { three-level structure }\end{array}$ & $\begin{array}{l}\text { M. Assimilates three } \\
\text { levels of units within } \\
\text { a task }\end{array}$ \\
\hline $\begin{array}{l}\text { B. Builds composite } \\
\text { units }\end{array}$ & $\begin{array}{l}\text { F. Indicates a } \\
\text { reciprocal relationship } \\
\text { between the size and } \\
\text { number of parts in a } \\
\text { whole }\end{array}$ & $\begin{array}{l}\text { J. Distributes } \\
\text { composite units }\end{array}$ & $\begin{array}{l}\text { N. Reflects on all } \\
\text { levels within a three- } \\
\text { level structure }\end{array}$ \\
\hline $\begin{array}{l}\text { C. Iterates composite } \\
\text { units }\end{array}$ & $\begin{array}{l}\text { G. Reverses } \\
\text { multiplicative } \\
\text { relationships }\end{array}$ & $\begin{array}{l}\text { K. Immediacy of } \\
\text { response }\end{array}$ & $\begin{array}{l}\text { O. Conflates or } \\
\text { confuses units }\end{array}$ \\
\hline $\begin{array}{l}\text { D. Uses multiplicative } \\
\text { relationships }\end{array}$ & $\begin{array}{l}\text { H. Builds a three-level } \\
\text { structure }\end{array}$ & $\begin{array}{l}\text { L. Flexibly works } \\
\text { with a three-level } \\
\text { structure }\end{array}$ & $\begin{array}{l}\text { P. References the } \\
\text { structure of units }\end{array}$ \\
\hline
\end{tabular}


Although we derived these descriptors from observed activity during the clinical interviews, many of them align with findings from previous research. For example, Steffe (1992) relied upon observations of students' activity with composite units to distinguish stages of units coordination: Whereas Stage 1 students might build composite units (descriptor B), students at Stages 2 and 3 can reliably iterate composite units (descriptor C) and even distribute one composite unit across the units of another composite unit (descriptor J). Hackenberg (2010) suggests that students at Stage 2 can use multiplicative relationships (descriptor D) and that some students at this stage can also reverse multiplicative relationships (descriptor G). She suggests that assimilating three levels of units (descriptor $\mathrm{M}$ ) is a defining characteristic of Stage 3. Our use of these descriptors in ranking students' units coordinating activity affirms their value by indicating how they might provide developmental indicators of students' units coordinating operations.

Steffe's (1992) work suggests that we should expect students to build composite units through activity before they can iterate and distribute composite units. We should expect them to begin working with multiplicative relationships at about the same time, but well before they begin reversing multiplicative relationships (Hackenberg, 2010). Still later, they might begin assimilating three levels of units within a task. As indicated in Appendix A, the cross-section of students in our study exhibited a similar pattern of development: Positive results for descriptor B appear before those of descriptors $\mathrm{C}$ and $\mathrm{D}$, which appear before those of descriptor $\mathrm{G}$ and then M (once we completed our analysis, we assigned them alphabetically based on order of appearance in the ranking). Only descriptor $\mathbf{J}$ (distributing composite units) violates the pattern, appearing after descriptor $\mathrm{G}$ (reversing multiplicative relationships), but then descriptor $\mathrm{G}$ 
appears consistently only after descriptor J does. Thus, it seems that students may begin reversing multiplicative relationships in tandem with distributing composite units.

Our study contributes additional distinctions within existing research on units coordination by including additional descriptors and qualifiers. For example, qualifiers within descriptor $\mathrm{O}$ indicate that students at ranks 11 through 20 conflate units (e.g., treating rows as seats in the classroom task). Rather than suggesting a regression in their ways of operating, conflating units may suggest that students are beginning to attend to a higher level of unitssometimes conflating units at that level with units at lower levels. In fact, ranks 11 through 20 coincide with new activity associated with descriptors $\mathrm{G}, \mathrm{H}, \mathrm{I}$, and $\mathrm{J}$ : reversing multiplicative relationships, building three-level structures, working with two levels within a three-level structure, and distributing composite units. At rank 19, Carly's case fits into this range. Carly had begun reversing multiplicative relationships; she built three-level structures; and she could work with two levels of units within such structures. Her inability to explain her reasoning and her reliance on figurative material suggest that these were new activities for her. We also find evidence that Carly conflated units in the context of these activities (e.g., confusing the number of rows with the number of seats in each row, in the classroom task). Thus, Carly's case may illustrate a phenomenon in which students begin conflating units when working with units in new ways, especially when a higher level of units is involved.

The descriptor, references the structure of units (descriptor P), qualifies the degree to which students explicitly refer to various levels of units in explaining their solutions. For instance, Carly made implicit reference to levels of units in explaining her solutions to the bars tasks ("the yellow bar fits into the red bar four times"), but her explanations often devolved into numerical justifications for choosing one operation over another (choosing multiplication over 
addition because multiplication produces 12 , which looks right, and addition produces only 7 ). Within this descriptor, three or four cycles appear across the ranks (see Appendix A). Like the apparent regression in the conflating units descriptor, the cycles in this descriptor may suggest new challenges associated with attention to higher levels of units: With each new level of units students attend to, they begin a new progression from awareness, to implicit reference, to explicit reference, and finally to explanation.

Each of the descriptors in Table 3 arose from the first phase of our study, during which the first two authors used the first set of interviews to develop rankings, characterizations, and descriptors for students' units coordinating activity. The reliability of these constructs was established during the second phase of the study, during which the fourth and fifth authors ranked the same 47 students based on their activity during the second set of interviews. Although the Spearman's rank coefficient (0.808) indicates a strong positive association between the two sets of assessments, the association is not perfect. With 16 of the 47 rankings off by seven or more, questions arise about the degree of granularity we can reliably achieve in distinguishing students' units coordinating activity.

\section{Granularity in Units Coordinating Activity}

Given the relatively high Spearman rank coefficient between the first two raters' rankings (0.929), we could attribute disparity between the first and second pairs of rankings to three factors: student development (or regression) in units coordination ability between the first and second interviews; variance in students' units coordinating activity within each stage; and ambiguities in the descriptors and characterizations. Concerning the first factor, we note no significant change in students' units coordination ability. This is not surprising given the relative intransigence in students' stages of units coordination (Steffe \& Cobb, 1988; Steffe \& Olive, 
2010), but we had hoped that our finer grained distinctions would help us identify a finer-grained development of units coordinating activity within each of those stages.

Carly's case is one of the 16 cases in which we found a difference of 7 or more ranks: The first pair of raters had ranked her at 19 (out of 36), and the second pair ranked her at 12. As one of those latter raters noted, Carly seemed to iterate composite units in visual activity (coded Green in Column C, in Appendix A), use multiplicative relationships implicitly (coded Yellow in Column D), reverse multiplicative relations inconsistently (coded Yellow in Column G), and conflate units often (coded Red in Column O). Although these descriptions do not differ dramatically from those of the initial raters, they yield a seven rank regression.

Carly's case suggests that variability in students' units coordinating activity within a developmental stage accounts for at least some of the disparity between our first and second rankings. In particular, students at Stage 2 are beginning to consider a third level of units, to distribute composite units, and reverse multiplicative relationships (Hackenberg, 2010; Hackenberg \& Tillema, 2009), so we might expect inconsistency in those activities until they are solidified within a three-level structure for operating. On the other hand, we found better agreement in most of the other cases, suggesting that most students demonstrated greater consistency in their units coordinating activity.

Potential ambiguities in descriptors (Appendix A) and characterizations (Appendix B) were noted by the third and fourth authors as they completed their rankings. For example, in reference to using multiplicative relations, qualifiers such as "implicit" and "explicit" were found to be highly subjective (as attested by the disparity in use of these terms in Carly's case). Also, sometimes the raters felt that the characterizations did not fit well with the descriptors, so they tended to rely upon the table of descriptors (Appendix A) instead. Because the characterizations 
were not intended as comparisons between students and some of these characterizations were collapsed across students (as rankings merged), the table of descriptors provides a better tool for ranking units coordinating activity.

Given the disparities illustrated in Figure 6, we cannot ascribe uniform granularity to our distinctions in units coordinating activity, but we do note differences in activity that occur around stage progressions from Stage 1 to Stage 2 and from Stage 2 to Stage 3. These regions are indicated by the two rectangular boundaries in Appendix A. The first region is bounded by descriptors $\mathrm{G}$ through $\mathrm{J}$ and rankings 12 through 23- the progression from Stage 1 activity to Stage 2 activity. Note that Carly's observed activity places her in the middle of this region, so our descriptions of her activity characterize much of the activity in this region. It seems that students transitioning to Stage 2 begin to engage in activities that involve building three-level structures (descriptor $\mathrm{H}$ ) and working with two levels of units within that structure (descriptor J); they also begin to reverse multiplicative relationships (descriptor $\mathrm{G}$ ) and distribute composite units (descriptor $\mathrm{K}$ ). The second region is bounded by descriptors $\mathrm{K}$ through $\mathrm{N}$ and rankings 24 through 35- the progression from Stage 2 activity to Stage 3 activity. So, it seems that students transitioning to Stage 3 begin to demonstrate greater responsiveness (descriptor K), flexibility (descriptor L), and flexibility (descriptor N) as they begin to assimilate three levels of units (descriptor M). In the next section, we consider what these regions and related findings imply for supporting students' development toward operating at Stages 2 and 3.

\section{Implications for Instruction}

As we have noted, the experience of the second set of raters (third and fourth authors) suggests that the 16 descriptors may provide the greatest utility; and many of these descriptors 
appear in previous research (e.g., Biddlecomb, 2002; Hackenberg, 2010; Hunting, 1983; Steffe, 1992). The present study helps us understand how those descriptors relate within a progression of units coordinating activity and how educators might promote such progress.

First, we note that instruction as usual is unlikely to affect any kind of progress in units coordinating activity: Students in our study demonstrated no significant change in their units coordinating activity, even on a 36-scale ranking and even with three months between the first and second interviews. Previous research on promoting units coordination suggests at least one productive avenue: challenging students with tasks that involve a multi-level structure (at least from the teacher's point of view) and providing students with figurative material for working with one, two, or three levels of units within that structure (Norton \& Boyce, in review; Steffe, 1992).

Working within a figurative three-level structure opens possibilities for students to engage in numerous units coordinating activities. In the region associated with the transition from Stage 1 to Stage 2 (G-K: 12-23, in Appendix A), students engage in working with two levels of units within such structures, and they begin to build their own three-level structures. Teachers might promote development toward Stage 2 by introducing tasks that include three or more levels of embedded units (at least from the teacher's perspective) and encourage students to investigate various two-level relationships, including the reversal of those relationships. All the while, teachers should be cognizant of the fact that students will often conflate units within those structures and that such conflations might indicate development, as students begin to attend to a third level of units. Sophian (2004) has noted similar units conflations in children's development of early number knowledge. 
The regions associated with the transition from Stage 1 to Stage 2 (K-N: 24-35, in Appendix A) does not introduce as much new activity. Rather, this transition is characterized by increased proficiency in working across three levels of units. This characterization aligns with the defining feature of operating at Stage 3; namely, students operating at Stage 3 can assimilate three levels of units and maintain the relationships between them in further activity, whereas students operating at Stage 3 have to build up the three-level relationships through activity. Thus, it seems that students transitioning to Stage 3 need the opportunities to build three-level structures within situations that involve at least four levels of embedded units (at least from the teacher's perspective). Teachers might be able to address the needs of both groups of studentsthose transitioning to Stage 2 and those transitioning to Stage 3-by providing such situations, with the expectation that students transitioning to Stage 2 would work with two levels at a time while students transitioning to Stage 3 would work with three levels at a time.

\section{Limitations}

Our study provides an initial, conjectured progression in students' units coordinating activity as they develop toward units coordinating Stage 3. Although we have provided evidence for the construct validity and reliability of our assessments, many of the stage rankings differed considerably from the first set of interviews to the second set of interviews and further study would be required to disentangle potential contributing factors. Were disagreements a product of variability in students' activity across time (including student growth/regression), inter-rater reliability (between the first and second pairs of raters), or limited validity in the initial rankings?

Our study does not allow us to disentangle these factors because we used a second pair of raters 
for the second set of interviews (to address potential rater bias) and because we used only one set of tasks, collectively, to form our assessments.

Future research might also elucidate why particular activities seem to coincide and whether preceding activities are prerequisite for succeeding ones. For example, initial activity in iterating composite units (descriptor $\mathrm{C}$ ) appears to be succeeded by initial activity in reversing multiplicative relationships (descriptor $\mathrm{G}$ ), at which point the two activities seem to develop in tandem with one another. Hackenberg's work (e.g., 2010) suggests that iterating composite units is the basis for operating with the second multiplicative concept, wherein students might begin reversing multiplicative relations. Our results affirm Hackenberg's suggestions, and conversely, her work explains some of our findings. Other activity progressions suggested by our findings require similar investigation and explanation.

\section{Acknowledgements}

This work is supported by the National Science Foundation (NSF) under Grant No. DRL1118571, and the Institute for Society, Culture and Environment (ISCE) at Virginia Tech. Any opinions, findings, and conclusions or recommendations expressed in this material are those of the authors and do not necessarily reflect the views of NSF or ISCE. The authors would also like to thank Amy Hackenberg for contributing her thoughts and responses to our work.

\section{References}

Best, D. J., \& Roberts, D. E. (1975). Algorithm AS 89: The upper tail probabilities of Spearman's rho. Applied Statistics, 24, 377-379. 
Biddlecomb, B. D. (2002). Numerical knowledge as enabling and constraining fraction knowledge: An example of the reorganization hypothesis. The Journal of Mathematical Behavior, 21(2), 167-190.

Boyce, S., \& Norton, A. (in review). Simultaneity in the Construction of Units Coordination Structures. The Journal of Mathematical Behavior.

Clement, J. (2000). Analysis of clinical interviews: Foundations and model viability. In A. E. Kelly \& R. A. Lesh (Eds.), Handbook of research design in mathematics and science education (pp. 547 - 589). NJ: Erlbaum.

Cohen, J. (1960). Weighted kappa: Nominal scale agreement with provision for scales disagreement of partial credit. Psychological Bulletin, 70, 213-220.

Ellis, A. B. (2007). The influence of reasoning with emergent quantities on students' generalizations. Cognition and Instruction, 25, 439 - 478.

Hackenberg, A. J. (2007). Units coordination and the construction of improper fractions: A revision of the splitting hypothesis. The Journal of Mathematical Behavior, 26(1), 27-47.

Hackenberg, A. J. (2010). Students' reasoning with reversible multiplicative relationships. Cognition and Instruction, 28(4), 383-432.

Hackenberg, A. J. (2013). The fractional knowledge and algebraic reasoning of students with the first multiplicative concept. The Journal of Mathematical Behavior, 32(3), 538-563.

Hackenberg, A. J., \& Lee, M. Y. (2015). How does students' fractional knowledge influence equation writing? Journal for Research in Mathematics Education, 46(2), 199-243.

Hackenberg, A. J., \& Tillema, E. S. (2009). Students' whole number multiplicative concepts: A critical constructive resource for fraction composition schemes. The Journal of Mathematical Behavior, 28(1), 1-18. 
Hunting, R. P. (1983). Alan: A case study of knowledge of units and performance with fractions. Journal for Research in Mathematics Education, 14(3), 182-197.

Izsák, A., Jacobsen, E., de Araujo, Z., \& Orrill, C. H. (2012) Measuring mathematical knowledge for teaching fractions with drawn quantities. Journal for Research in Mathematics Education, 43(4).

Landis, J. R., \& Koch, G. G. (1977). The measurement of observer agreement for categorical data. Biometrics, 33(1), 159-174.

Norton, A., \& Boyce, S. (2013). A cognitive core for common state standards. Journal for Mathematical Behavior, 32, 266-279.

Norton, A., \& Boyce, S. (in review). Provoking the construction of a structure for coordinating $n+1$ levels of units. Cognition \& Instruction.

Olive, J. \& Çağlayan, G. (2008). Learner's difficulties with quantitative units in algebraic word problems and the teacher's interpretations of those difficulties. International Journal of Science and Mathematics Education, 6, 269-292. doi:10.1007/s10763-007-9107-6

Olive, J., \& Vomvoridi, E. (2006). Making sense of instruction on fractions when a student lacks necessary fractional schemes: The case of Tim. The Journal of Mathematical Behavior $25(1), 18-45$.

Piaget, J. (1970). Genetic epistemology. New York: Columbia University Press.

R Core Team (2012). R: A language and environment for statistical computing. Vienna, Austria: R Foundation for Statistical Computing. Retrieved from http://www.R-project.org/.

Sophian, C. (2004). A prospective developmental perspective on early mathematics instruction. Engaging young children in mathematics: Standards for early childhood mathematics education, 253-266. 
Steffe, L. P. (1992). Schemes of action and operation involving composite units. Learning and Individual Differences, 4(3), pp. 259-309.

Steffe, L. P. (1994). Children's Multiplying Schemes. In G. Harel \& J. Confrey (Eds.), The development of multiplicative reasoning in the learning of mathematics (pp. 3-39). Albany, NY: SUNY Press.

Steffe, L. P. (2001). A new hypothesis concerning children's fractional knowledge. The Journal of Mathematical Behavior, 20(3), 267-307.

Steffe, L. P. (2007, April). Problems in mathematics education. Paper presented for the Senior Scholar Award of the Special Interest Group for Research in Mathematics Education (SIG-RME) at the annual conference of the American Educational Research Association in Chicago, Illinois.

Steffe, L. P., \& Cobb, P. (1988). Construction of arithmetical meanings and strategies. New York, NY: Springer.

Steffe, L. P., \& Olive, J. (2010). Children's fractional knowledge. Springer: New York.

Tillema, E. S. (2013). A power meaning of multiplication: Three eighth graders' solutions of Cartesian product problems. The Journal of Mathematical Behavior, $32(3), 331-352$.

Ulrich, C. (2012). The addition and subtraction of signed quantities. In R. Mayes \& L. Hatfield (Eds.), Quantitative reasoning and mathematical modeling: A driver for STEM integrated education and teaching in context (pp. 127-141). Laramie, WY: University of Wyoming. Available at http://www.uwyo.edu/wisdome/_files/documents/ulrich.pdf

Ulrich, C. (2013). Additive versus multiplicative units coordination: An elaboration of existing frameworks and recent findings. In L. Hatfield, K. Moore, and L. P. Steffe (Eds.), 
Wyoming Institute for the Study and Development of Mathematical Education

(WISDOM^e) Monograph (Vol. 4) Laramie, WY: University of Wyoming, College of

Education. 


\section{Appendix A: Descriptors and Rankings}

\begin{tabular}{|c|c|c|c|c|c|c|}
\hline Column & Descriptor & Red & Orange & Yellow & Green & Blue \\
\hline $\mathbf{A}$ & Iterates units of 1 & No & & $\begin{array}{l}\text { Using figurative } \\
\text { material }\end{array}$ & $\begin{array}{l}\text { In visual } \\
\text { activity }\end{array}$ & $\begin{array}{l}\text { In } \\
\text { anticipation }\end{array}$ \\
\hline $\mathbf{B}$ & Builds composite units & No & & $\begin{array}{l}\text { Using figurative } \\
\text { material }\end{array}$ & & $\begin{array}{l}\text { In } \\
\text { anticipation }\end{array}$ \\
\hline $\mathbf{C}$ & Iterates composite units & No & & $\begin{array}{l}\text { Using figurative } \\
\text { material }\end{array}$ & $\begin{array}{l}\text { In visual } \\
\text { activity }\end{array}$ & $\begin{array}{l}\text { In } \\
\text { anticipation }\end{array}$ \\
\hline D & $\begin{array}{l}\text { Uses multiplicative } \\
\text { relationships }\end{array}$ & No & & Implicitly & & Explicitly \\
\hline $\mathbf{E}$ & $\begin{array}{l}\text { Works with at least one } \\
\text { level of units within a } \\
\text { figurative three-level } \\
\text { structure }\end{array}$ & No & & & & Yes \\
\hline $\mathbf{F}$ & $\begin{array}{l}\text { Indicates a reciprocal } \\
\text { relationship between the } \\
\text { size and number of parts } \\
\text { in a whole }\end{array}$ & No & & & & Yes \\
\hline $\mathbf{G}$ & $\begin{array}{l}\text { Reverses multiplicative } \\
\text { relationships }\end{array}$ & No & & Inconsistently & & Yes \\
\hline $\mathbf{H}$ & $\begin{array}{l}\text { Builds a three-level } \\
\text { structure }\end{array}$ & No & & $\begin{array}{l}\text { Using figurative } \\
\text { material }\end{array}$ & & Yes \\
\hline $\mathbf{I}$ & $\begin{array}{l}\text { Works with at least two } \\
\text { levels of units within a } \\
\text { figurative three-level } \\
\text { structure }\end{array}$ & No & & & & Yes \\
\hline $\mathbf{J}$ & $\begin{array}{l}\text { Distributes composite } \\
\text { units }\end{array}$ & No & & & & Yes \\
\hline $\mathbf{K}$ & Immediacy of response & Delayed & & Moderate & $\begin{array}{l}\text { Somewhat } \\
\text { quick }\end{array}$ & Immediate \\
\hline $\mathbf{L}$ & $\begin{array}{l}\text { Flexibly works with a } \\
\text { three-level structure }\end{array}$ & Limited & $\begin{array}{l}\text { Somewhat } \\
\text { limited }\end{array}$ & Moderate & $\begin{array}{l}\text { Somewhat } \\
\text { fluent }\end{array}$ & Fluent \\
\hline M & $\begin{array}{l}\text { Assimilates three levels } \\
\text { of units within a task }\end{array}$ & No & & & & Yes \\
\hline $\mathbf{N}$ & $\begin{array}{l}\text { Reflects on all levels } \\
\text { within a three-level } \\
\text { structure }\end{array}$ & No & & $\begin{array}{l}\text { Such activity } \\
\text { seems novel }\end{array}$ & & Yes \\
\hline $\mathbf{O}$ & $\begin{array}{l}\text { Conflates or confuses } \\
\text { units }\end{array}$ & Often & & Occasionally & & No \\
\hline $\mathbf{P}$ & $\begin{array}{l}\text { References the structure } \\
\text { of units }\end{array}$ & No & $\begin{array}{l}\text { Aware of } \\
\text { structure }\end{array}$ & $\begin{array}{l}\text { Implicit } \\
\text { reference }\end{array}$ & $\begin{array}{l}\text { Explicit } \\
\text { reference }\end{array}$ & Explanatory \\
\hline
\end{tabular}




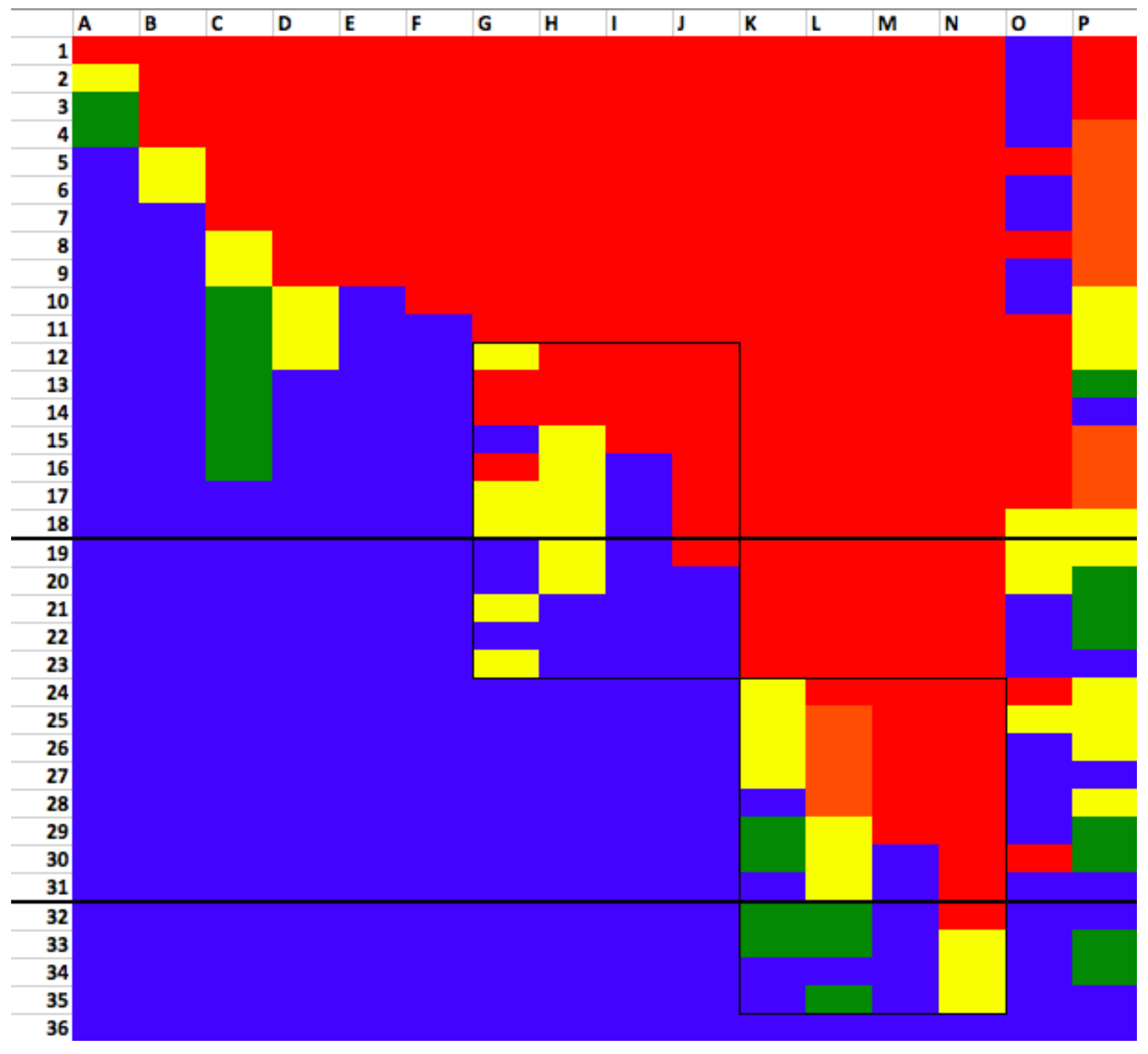




\section{Appendix B: Qualitative Characterizations for Each Rank}

1. The student does not iterate units of 1, even in activity with figurative material available. He might count a collection in his perceptual field, producing a one-to-one correspondence between pointing acts and number words, but the result is not yet a fixed quantity.

2 . The student can take figurative material and treat it as an iterable unit of 1 , in activity, but he cannot do this in imagination.

3. The student can treat figurative material as an iterable unit of 1 in his imagination. Likewise, he can iterate a unit of 1 in activity to form or decompose collections. However, the novelty of this activity is evident in mistakes (e.g., losing track of iterations).

4. The student can reliably treat figurative material as an iterable unit in imagination. The student does not produce different levels of units, even in activity, but seems aware that different levels exist.

5. The student can make copies of a composite unit, produced through activity, by relying on figurative material, but often confuses or conflates units.

6. The student can imagine producing units of units in activity but does not produce a multiplicative structure to relate them. The student attempts to build a two level structure using figurative material but distributes the units by 1 .

7. The student begins to build a two level structure without the use of figurative material but the only reliable unit for solving novel problems is a unit of 1 . The student builds up composite units from a unit of 1 , but cannot build a three-level structure even using figurative material. No distinctions are made between levels of units, except between the unit of 1 and the composite units they produce through iteration.

8. The student begins to iterate composite units in activity, in special cases such as 2 , but sometimes conflates this unit with a unit of 1 . Also, the iterations of a composite unit produce a partitioned line rather than a two-dimensional array.

9. The student can treat figurative material as a composite unit and can keep track of iterations of that unit, counting by the composite number (in general, not just for special numbers like 2).

10. The student seems to have an intuition about the multiplicative relationship within iterations of a composite unit but cannot explicitly describe its structure or explain the relationship, and the student cannot reverse this relationship. Neither can the student reliably coordinate two levels of units within a three-level structure.

11. The student begins to understand the reciprocal relationship between the size of the unit and its numerical relationship with the size of a composite unit produced through iteration. The student still conflates units within problem situations that involve three levels of units. The student understands the reciprocal relationship between the number of times a one unit fits into another and the size of the iterated unit. The student can also iterate a composite unit in activity but determines the result using units of 1 .

12. The student seems to have an intuition about the multiplicative relationship between two levels of units, even when working in reverse, but this reasoning is inconsistent and not explicit.

13. The student begins to understand an explicit relationship between composite units and multiplication but still struggles when working in reverse. The student still conflates units when attempting to build a three-level structure. 
14. The student regularly builds up two-level structures through activity and can at least partially explain them and their relation to multiplication.

15. The student iterates composite units in activity keeping track by counting by the associated number. The student can use a similar strategy when working in reverse. But the student still conflates units when attempting to build a three-level structure.

16. The student readily coordinates two levels of units through activity but not when working in reverse. The student attempts to build up three-level structures using figurative material and can coordinate two levels at a time within that structure.

17. The student can treat a composite unit as a unit of 1 and iterate it while explicitly keeping track of the multiplicities. This activity is less consistent when working in reverse. The student still conflates units when attempting to assimilate situations involving three levels of units.

18. The student seems to have an intuition about the role of multiplication (or division) in iterating a composite unit (or reversing that activity) but is not explicitly aware of the connection (proficient use of iterating 1 might circumvent the need for a units coordination). However, the student can coordinate two units at a time to solve problems within a three-level structure.

19. The student reliably iterates composite units within multiplicative relationships. The student can use figurative material to build three level structures and use them unambiguously to solve problems, including working in reverse.

20. The student consistently iterates composite units and can consistently reverse that activity but has some trouble justifying its relation to a problematic situation. He can also strategically distribute composite units.

21. The students' facility in iterating a unit of 1 might circumvent the need to iterate composite units, but the student can build up a three-level structure through activity, relying on counting but not figurative material. The student might make mistakes in keeping track of the numbers of units, but does not conflate the levels of units.

22. The student consistently iterates a composite unit to produce a third-level unit and can reverse that way of acting, but has difficulty explaining the relationship in the reverse direction. Otherwise, the student does not seem to build any three-level structures, even in activity, at least not without the aid of figurative material. The student can engage in reversible multiplicative reasoning except in cases where the number of iterations is unknown. The student can build three-level structures in activity, with the aid of figurative material.

23. The student can iterate composite units and explain their relation to the resulting unit, but does not reliably reverse this way of operating. The student can build up a three-level structure from units of 1 by segmenting the composite units in activity, using fingers and language to monitor, but the student sometimes conflates units.

24. The student can relate the iteration of composite units to multiplication and division and explain the relationship with some ambiguity. Readily works with composite units and can use figurative material to produce a three-level structure, but sometimes loses track of units as if working memory is taxed when working with multiple two-level structures. 25 . The student readily iterates composite units and can relate this to multiplication, even when working in reverse, though this remains problematic when the number of iterations of the composite unit is the unknown. The student can also build up a third level of units by iterating a composite unit, coordinating all three levels through activity, but such activity 
puts great demands on the students' working memory and the student cannot consistently explain the relationships between the units.

26. The student readily iterates composite units and can reverse this way of operating, even when determining the number of iterations of a composite unit, but the student has trouble explaining the relationships when working in reverse. The student can coordinate three levels of units in activity, but may rely on figurative material to do so.

27. The student can iterate composite units and keep track of the iterations by counting by the associated number, and can do the same when working in reverse. The student can work with three levels of units by using figurative material to represent one of the composite units.

28. The student can immediately relate situations involving the iteration of a composite unit to multiplication and division, though he does not necessarily explain the relationship. When three levels of units are given, the student has trouble keeping track of all three levels and must work with two at a time, building up the third level through activity. 29. The student has no trouble iterating composite units, even when working in reverse, except when the number of iterations is unknown, in which case the student may feel inclined to rely on figurative material to determine the number. The student can also keep track of three levels of units and coordinate them, at least in activity, without relying on figurative material.

30. The student can readily solve problems involving the iteration of a composite unit, even in reverse tasks where the iterated unit or the number of iterations is unknown. He can also explain each of these, except in the last case. He can assimilate tasks involving three levels of units, but seems to have trouble keeping track of all of the units and relationships within the three-level structure.

31. The student can readily solve problems involving the iteration of a composite unit, even in reverse tasks where the iterated unit or the number of iterations is unknown, and he can also explain each of these with reference to figurative material. The student can also iterate composite units in order to build up three levels of units in activity.

32. The student can readily solve problems involving the iteration of a composite unit and can explain each of these with reference to figurative material. In reverse tasks, this takes longer, indicating that the student has to consciously reverse this way of operating, especially when the number of iterations is unknown. The student can assimilate situations involving three levels of units and can move flexibly within this structure.

33. The student can assimilate any situation involving three levels of units without engaging in any physical activity. He can keep track of the units, their iterations, and their relationships, but this activity involves high cognitive demand. The student provides convoluted explanations for tasks that involve an unknown number of iterations of a composite unit, possibly indicating the novelty of reflecting on a three-level structure. 34. The student can readily assimilate and solve problematic situations involving three levels of units, though he cannot necessarily explain his reasoning and does not always reflect on his activity in solving the problems.

35. The student can readily assimilate and solve many problematic situations involving three levels of units and provides thoughtful explanations for his reasoning. However, some of the more complex tasks (tasks involving iterating a composite unit an undetermined number of times) might require more time, effort, and activity. 
36. The student can readily assimilate and flexibly solve problematic situations involving three levels of units, with little apparent effort. Moreover, he can provide thoughtful, reflective explanations for his reasoning. 